\title{
Concentration Dependence of a Novel Hydrogel Phase Formed by the Deprotonation of the Imidazole Side Chain of Glycylhistidylglycine
}

\author{
Morgan Hesser ${ }^{1}$, Lavenia Tursch ${ }^{2}$, Todd Lewis' ${ }^{2}$, Thamires \\ Lima $^{2}$, Nicolas Alvarez ${ }^{2}$ and Reinhard Schweitzer-Stenner ${ }^{1 *}$ \\ ${ }^{1}$ Department of Chemistry and ${ }^{2}$ Department of Chemical and Biological \\ Engineering, Drexel University, Philadelphia, PA 19104, USA
}

Supporting Information

\footnotetext{
*Corresponding author: Reinhard Schweitzer-Stenner, Phone: 215-895-2268; Email: rs344@drexel.edu
} 


\begin{tabular}{|l|l|l|l|l|l|}
\hline $\begin{array}{c}\text { Stock } \\
\text { Solution }\end{array}$ & $\begin{array}{c}\text { Concentration } \\
\mathrm{GHG}(\mathrm{mM})\end{array}$ & $\mathrm{pH}^{*}$ & $\begin{array}{c}\text { Mass } \\
\mathrm{GHG} \\
(\mathrm{mg})\end{array}$ & $\begin{array}{c}\text { Volume } \mathrm{D}_{2} \mathrm{O} \\
(\mu \mathrm{L})\end{array}$ & Volume $\mathrm{DCl}(\mu \mathrm{L})$ \\
\hline $\mathrm{A}$ & 402.9 & 2.89 & 505.8 & 4400 & 262 \\
\hline $\mathrm{B}$ & 402.9 & 2.39 & 252.88 & 2200 & 131 \\
\hline $\mathrm{C}$ & 402.5 & 2.23 & 187.28 & 1629 & 99 \\
\hline $\mathrm{D}$ & 402.4 & 2.25 & 271.3 & 2357 & 147 \\
\hline $\mathrm{E}$ & 402.7 & 2.64 & 183.67 & 1597 & 97 \\
\hline
\end{tabular}

Table S1: List of different of stock solutions used for gelation experiments described in the main manuscript.

\begin{tabular}{|r|c|c|r|r|r|r|}
\hline $\begin{array}{c}\text { Sample } \\
\begin{array}{c}\text { oncentration } \\
(\mathrm{mM})\end{array}\end{array}$ & $\mathrm{pH}^{*}$ & Stock Solution & $\begin{array}{c}\text { Volume Stock } \\
(\mu \mathrm{L})\end{array}$ & $\begin{array}{c}\text { Volume } \\
\mathrm{D}_{2} \mathrm{O} \\
(\mu \mathrm{L})\end{array}$ & NaOD Dilution Factor & Volume NaOD $(\mu \mathrm{L})$ \\
\hline 74.9 & 6.67 & $\mathrm{~A}$ & 93 & 372 & $1 / 10$ & 35 \\
\hline 74.9 & 6.97 & $\mathrm{~A}$ & 93 & 366 & $1 / 10$ & 41 \\
\hline 75.1 & 7.38 & $\mathrm{D}$ & 79.6 & 300 & $1 / 10$ & 47 \\
\hline 175.0 & 6.33 & $\mathrm{~A}$ & 218 & 218 & $1 / 10$ & 66 \\
\hline 175.0 & 6.47 & $\mathrm{~A}$ & 218 & 213 & $1 / 10$ & 71 \\
\hline 175.1 & 6.84 & $\mathrm{C}$ & 174 & 150 & $1 / 10$ & 110 \\
\hline 299.9 & 5.70 & $\mathrm{~B}$ & 372 & 17.8 & $1 / 10$ & 120 \\
\hline 299.9 & 5.92 & $\mathrm{~B}$ & 372 & 7.8 & $1 / 10$ & 110 \\
\hline 299.9 & 6.13 & $\mathrm{~A}$ & 372 & 17.8 & $1 / 10$ & 55 \\
\hline 300.0 & 6.61 & $\mathrm{E}$ & 298 & 47 & $1 / 5$ & \\
\hline
\end{tabular}

Table S2: Parameters of samples prepared for the gelation experiments described in the main manuscript. 


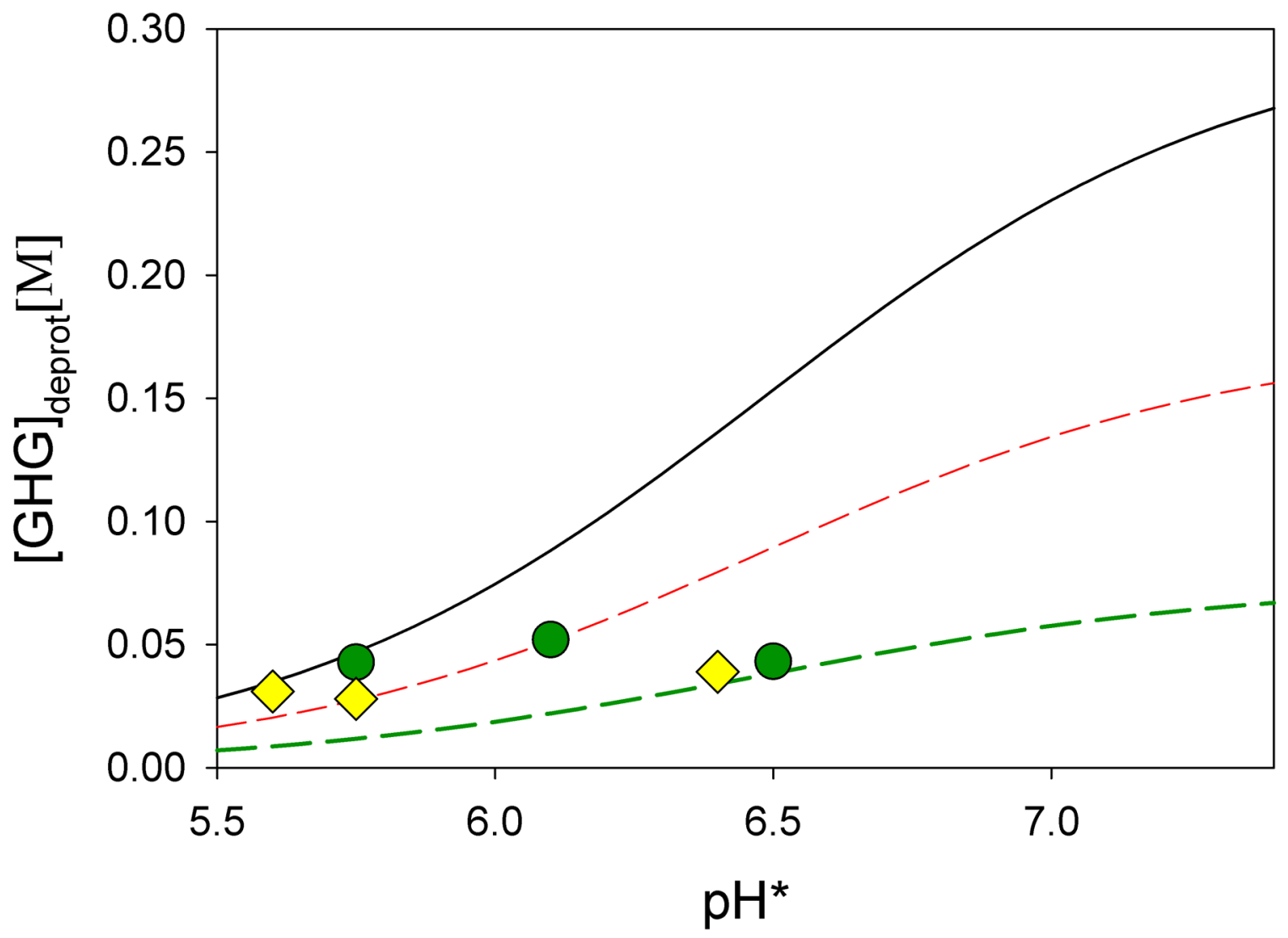

Figure S1 - Concentration of deprotonated GHG as a function of pH for $75 \mathrm{mM}$ (green short dash), 175 $\mathrm{mM}$ (red long dash), and $300 \mathrm{mM}$ (black line) total GHG concentration calculated with eq. (1) and a pK value of 6.48. The samples forming the full aggregation boundary of the well plate in Figure 1 are indicated by yellow diamonds (highest $\mathrm{pH}$ without full aggregation at given concentration) and green circles (lowest $\mathrm{pH}$ with full aggregation at given concentration). 


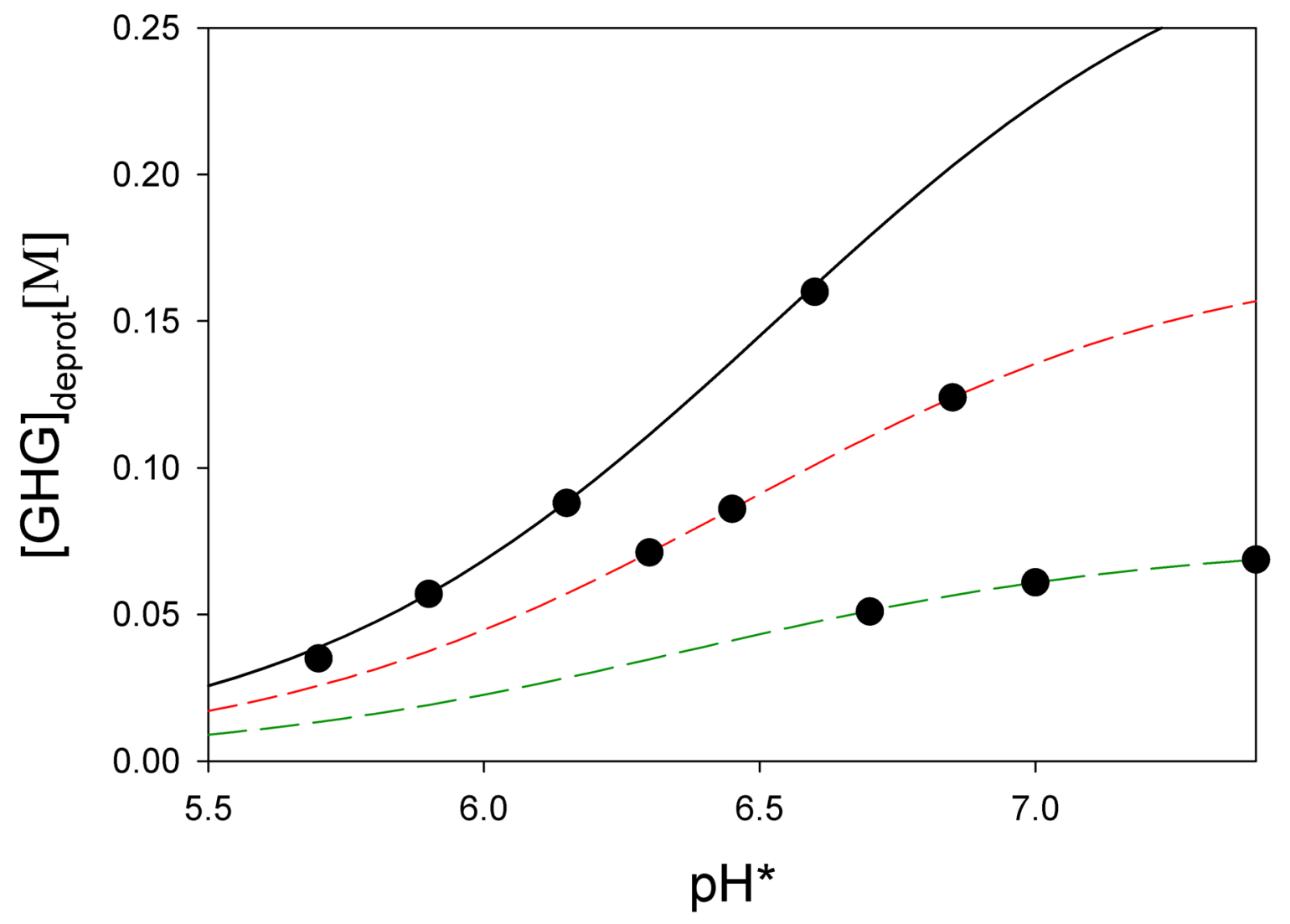

Figure S2: Titration curves plotting the concentration of deprotonated GHG as a function of the effective $\mathrm{pH}$ for [GHG]= $75 \mathrm{mM}$ (dashed green line), $175 \mathrm{mM}$ (dashed red line) and $300 \mathrm{mM}$ (solid line). The curves were calculated with equations 1 and 2 . The $\mathrm{pK}_{0}$ value was 6.0. The circular dots in the figure indicate the concentrations of deprotonated GHG for the $\mathrm{pH}^{*}$ values used in this study 


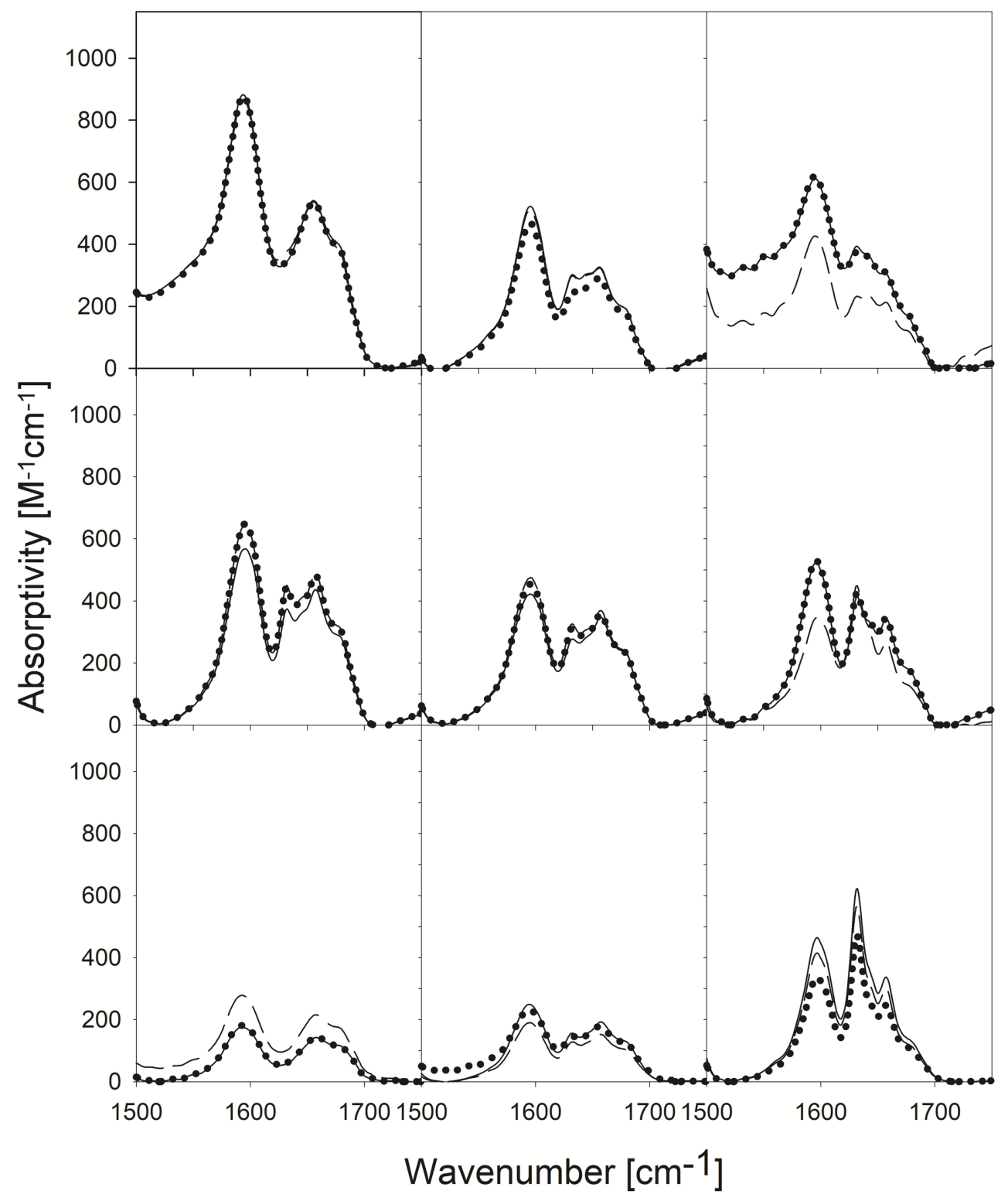

Figure S3: IR spectra of 75 (upper panel), $175 \mathrm{mM}$ (middle panel) $300 \mathrm{mM} \mathrm{GHG} \mathrm{(lower} \mathrm{panel)} \mathrm{at} \mathrm{pH}^{\star} 6.67$, 6.33, 5.70 (left), 6.97, 6.47, 5.92 (middle), and 7.38, 6.84, 6.13 (right) in the region between 1500 and 1750 $\mathrm{cm}^{-1}$. The sample was rotated approximately $120^{\circ}$ between scans, with the corresponding spectra labelled R1 (solid line), R2 (dashed), and R3 (dot). 


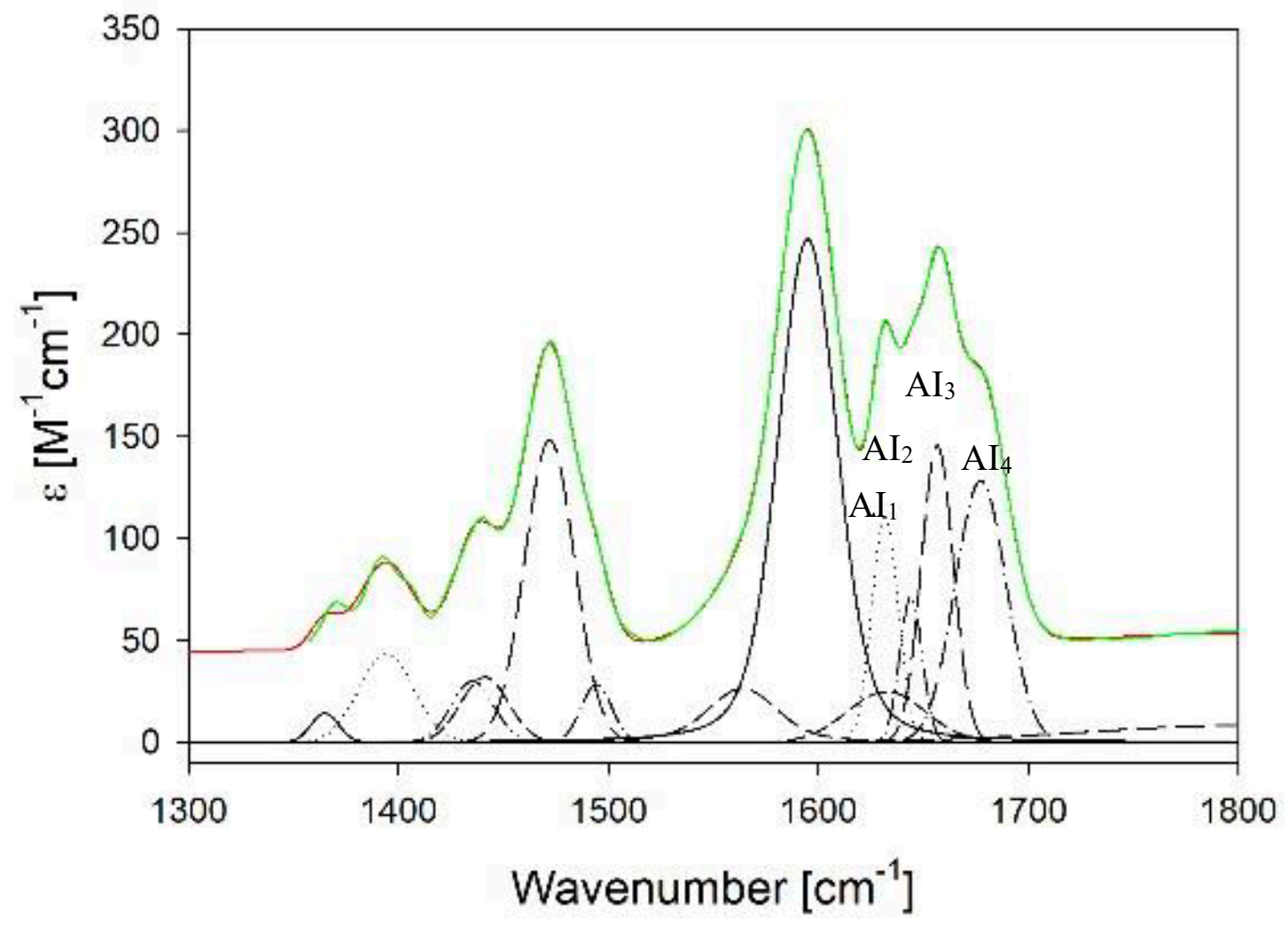

Figure S4: Representative spectral decomposition used to calculate relative intensity. The samples used are the first rotation (R1) of: $75 \mathrm{mM}$ GHG, pD 6.67 (upper panel), $175 \mathrm{mM}$ GHG, pD 6.33 (middle panel), and $300 \mathrm{mM} \mathrm{GHG}, \mathrm{pD} 5.92$ (lower panel). The green spectra are the original measured spectra, the red spectra are the fitted spectra, and the underlying bands are in black. Fit information is in Chapter 3 of this thesis. 


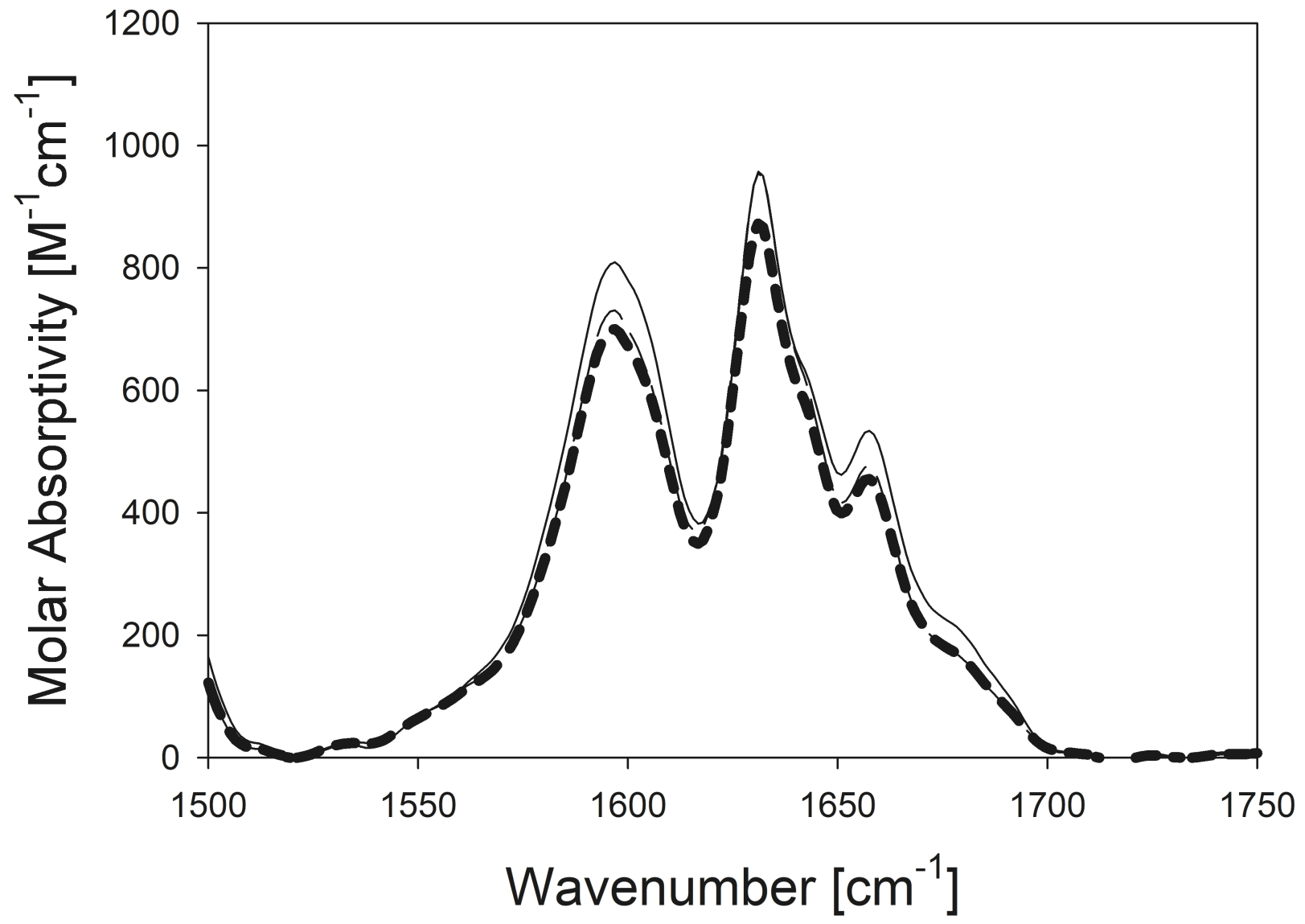

Figure S5: IR spectra of $300 \mathrm{mM} \mathrm{GHG}$ at $\mathrm{pH}^{\star} 6.61$ recorded between 1500 and $1750 \mathrm{~cm}^{-1}$ for three different cell orientations R1 (solid), R2 (dashed) and R3(dot). 


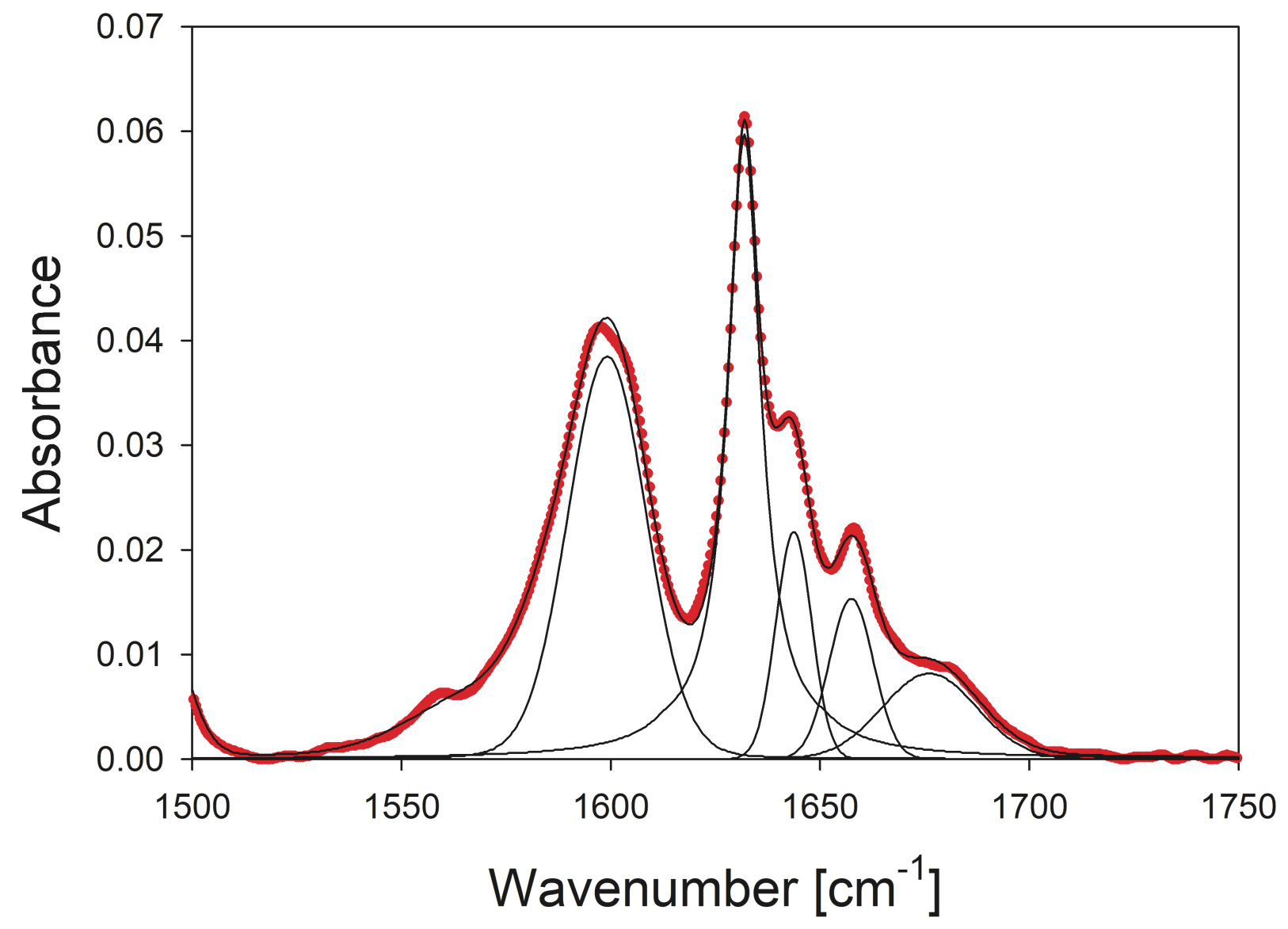

Figure S6: Decomposition of the FTIR spectrum of $175 \mathrm{mM}$ GHG measured with an ATR set up at $\mathrm{pH}^{*}$ 6.16 after an incubation time of $1018 \mathrm{~s}$. Additional spectra taken at different times to measure the kinetics of fibril formation are shown in the main manuscript. 

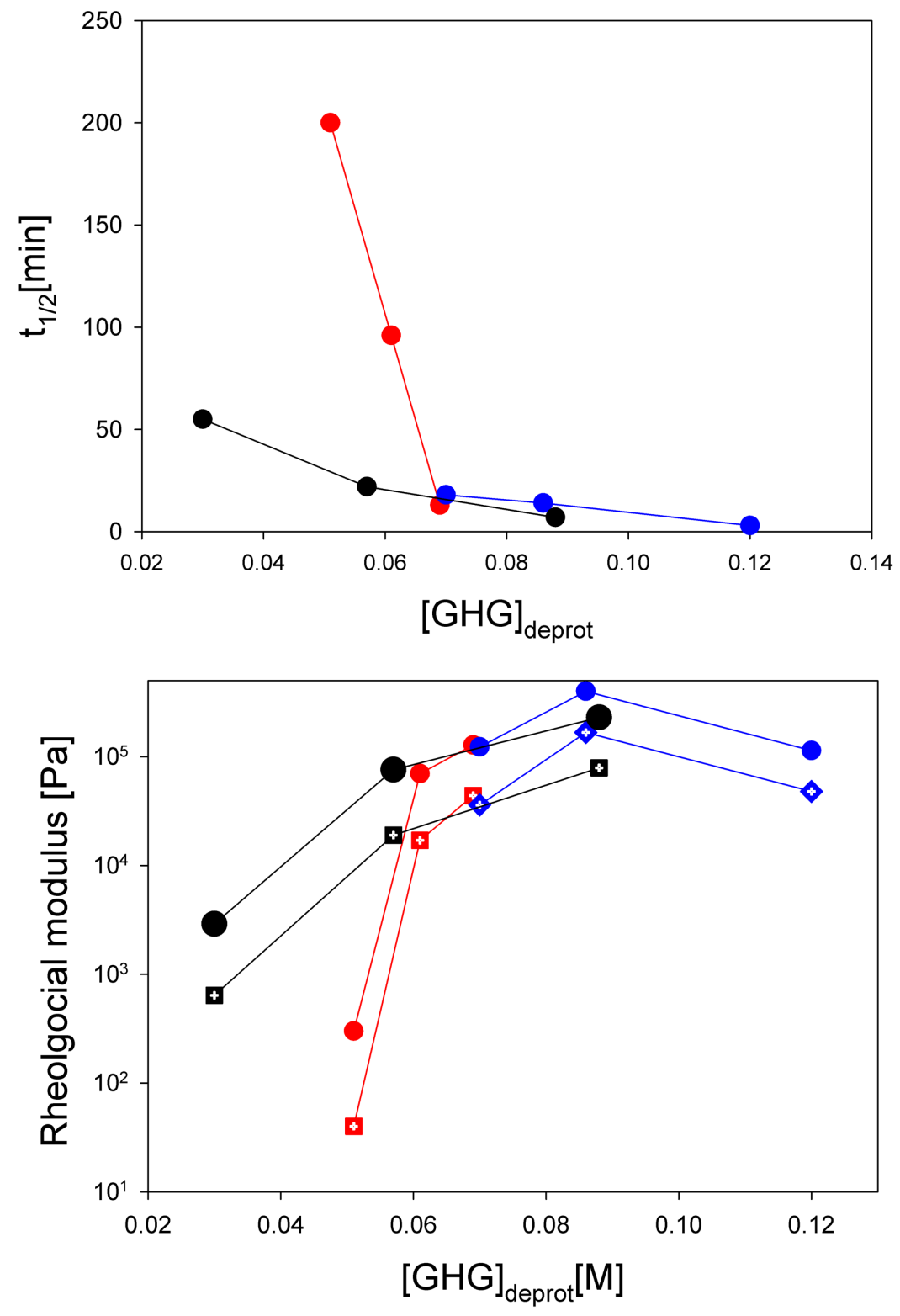

Figure S7: Half time of GHG gelation kinetics (upper panel) and rheological moduli (G': full circles, G" quadrants with cross hair; lower panel) plotted as a function of the concentration of deprotonated GHG as obtained with $75 \mathrm{mM}$ (red), $175 \mathrm{mM}$ (blue) and $300 \mathrm{mM}$ (black). 